\title{
Understanding place value with numeration units
}

\author{
Catherine Houdement ${ }^{*}$, Frédérick Tempier ${ }^{* *}$
}

\begin{abstract}
Numeration units (ones, tens, hundreds, etc.) are an epistemological foundation for place value. Here, we assume that they are a didactic support in countries where spoken numbers are incongruent with written numbers. In France, teaching practices neglect the relations between units, and numeration units are typically used only to designate the positions of digits. Our research, which adopts the didactical engineering framework, aims to develop a set of reference tasks for grades 1 to 5 to support a consistent learning of place value with numeration units. This article reports the theoretical framework on which our research is based, and illustrates it with some examples of tasks designed for grade 3 students and implemented in classrooms.
\end{abstract}

Keywords. Didactical engineering, Numeration units, Place value, Primary school, Task design, Unitizing.

\section{Introduction}

The current decimal and positional number system, known as the Hindu-Arabic system, is used worldwide for writing numerals. The origin of this notation remains a subject of debate among historians of mathematics. The counting rod rules that govern place value were initially presented in the Sunzi Suanjing, a Chinese mathematical treatise written during the $3^{\text {rd }}$ to $5^{\text {th }}$ centuries, which is thought to be the origin of the decimal system. The system reached India in the $5^{\text {th }}$ to $9^{\text {th }}$ centuries, the Arab Empire in the $10^{\text {th }}$ century, and then Europe in the $13^{\text {th }}$ century (Sun et al. 2018). But the integration of the place value system took more time. In France, as in other countries, at some point two 'number notation' systems coexisted, depending on the function (counting a collection, marking a date, computing, etc.). Proust (2000) named these systems of concrete and abstract numbers. For instance, in both France and England, counting was based on highly visual means of computation (tokens and a counting board), which were taught until the $18^{\text {th }}$ century (Ifrah 1981), whilst in France everyday number notation was based on the Roman system.

History suggests that the most plausible reason for the invention and use of a positional system for writing integers and decimals comes from its computational power (Stevin 1585, Menninger 1969). Algorithms that use numbers expressed in this way can be reduced to a calculation based on the digits, which considerably reduces the memory load in mental calculations. Many scholars assume that the choice of base-ten is linked to physical reasons and human cognition: hands have ten fingers (Ifrah 1981), and the products of one-digit numbers are easy to remember (Guitel 1975).

But what exactly is this system? In essence, it is a juxtaposition of digits (either zero or strictly less than ten), which is able to represent a quantity regardless of its size, and each digit also denotes a quantity. Place value makes this trick possible. The value of the digit changes according to its position in the number; the link between positional values is a power of ten. Place value can be illustrated as follows, with the number 333.3: from left to right the first digit denotes 300 , the second 30 , the third 3 and the fourth 0.3 . The understanding of this system is recognized by the research community as fundamental to grasping mathematics (e.g., Sun et al. 2015).

\footnotetext{
* Université Rouen Normandie, Laboratoire de Didactique André Revuz (EA-4434, France) UA-UCP-UPDUPEC-URN, catherine.houdement@univ-rouen.fr

** Université de Cergy-Pontoise, Laboratoire de Didactique André Revuz (EA-4434, France) UA-UCP-UPDUPEC-URN, frederick.tempier@u-cergy.fr
} 
The starting point is the notion of unit, the foundation of all number systems (Guitel 1975; Ifrah 1981; Fosnot and Dolk 2001). Ten ones form a new unit: one ten. Ten tens form another new unit: one hundred, etc. In this paper we use the following concept of the unit, (Ma and Kessel 2018, p. 442), "A single thing, or one, is called a unit or unit one. A group of things or a group of units, if considered as a single thing or one, is also called a unit, a unit one or a one." Ma and Kessel go on to define the number, "A number is a unit (one) or a collection of units (ones)" (p. 443).

A didactically convenient way to describe the value of each digit is to use what we call number units (Houdement and Chambris 2013) or numeration units (Chambris 2008; Houdement and Tempier 2015), by analogy with metric system units (length, mass). In this system, 372 can be described as 3 hundreds, 7 tens, and 2 ones (or 7 tens, 3 hundreds, and 2 ones, or...). In the literature different expressions have been used. For instance the multiunit (Fuson 1990, p. 347) denotes a number composed of many units, which are consistently unnamed in written numbers, but can be named in spoken numbers.

Place value in the decimal Hindu-Arabic system is based on two inseparable principles (Ross 1989):

- The position of each digit in a written number corresponds to a unit (for example hundreds are in the third place to the left of the decimal point): this is the positional principle;

- Each unit is equal to ten units of the immediately lower order (for example one hundred $=$ ten tens): this is the decimal principle.

As Fuson et al. (1997, p. 130) show, the coordination of the two principles is complex, particularly in European countries. How numeration units are taught could help. Although in France, the ones, tens, and hundreds are taught, it is only in terms of the position of a number, while the decimal principle is neglected. In a survey of 104 French third graders (8-9 years old), Tempier (2013) found a poor success rate for tasks involving relations between units (i.e., involving the decimal principal). Notably the question " 1 hundred $=\ldots$ tens" was correctly answered by $48 \%$ of students; $31 \%$ could solve " 60 tens $=\ldots$ hundreds"; and $39 \%$ were able to give the right answer to the problem "in 764 ones there are ... tens". Here, we argue that numeration units are mainly taught as the names of the positions of digits. A study of the French curriculum, combined with textbooks and teaching practices (Tempier 2013) supports this hypothesis: for instance, the 2008 French curriculum (grades 1 to 5) made no reference to place value principles before grade 3 (Houdement and Chambris 2013).

Our research examines how the introduction of numeration units and the relations between them in primary school (grades 1 to 5) can improve the understanding of place value. Our methodology is to design reference situations, according to the Theory of Didactical Situations (Brousseau 1997). Variations are provided for grades 1 to 5 , and the tasks should be easy to apply in day-to-day teaching, according to didactical engineering for development (Perrin-Glorian 2011).

This paper reports a consistent theoretical framework in mathematics education for considering the influence of numeration units on understanding place value. Various theories and pieces of research done in different perspectives are linked together in an epistemological and didactical analysis (sections 2 and 3). It provides a sound basis for designing reference situations (section 4). An experiment in grade 3 (section 5) illustrates the theoretical and task design choices. In fact, this is a theoretical paper with a few empirically used instructional examples.

\section{Theoretical framework for task design}

Didactical Engineering (Artigue 2009; Margolinas and Drijvers 2015) is a research method for task design based on classroom implementation, in other words, for the design, implementation, observation and analysis of teaching sequences. It can be seen as a particular case of Design Based Research (Godino et al. 2013), which is supported by the Theory of Didactical Situations (Brousseau 1997). Epistemological questions are crucial, while the validation method is mostly internal and 
performed through the comparison of a priori and a posteriori analyses. However, the use of this method to design tasks for day-to-day teaching has been criticized in France. In an attempt to overcome the problem, Perrin-Glorian (2011) put forward a method ("didactical engineering for the development of a resource and teacher education") designed to facilitate the use of resources in the classroom. Two properties are examined: the relevance of the situation (does the proposed situation enable students to construct the intended knowledge?); and the adaptability of the situation to dayto-day teaching (what adaptations do teachers make during the implementation of the situation?). We draw upon this method in our study. Like most design-based studies in mathematics education we use a cycle-based methodology (Figure 1).

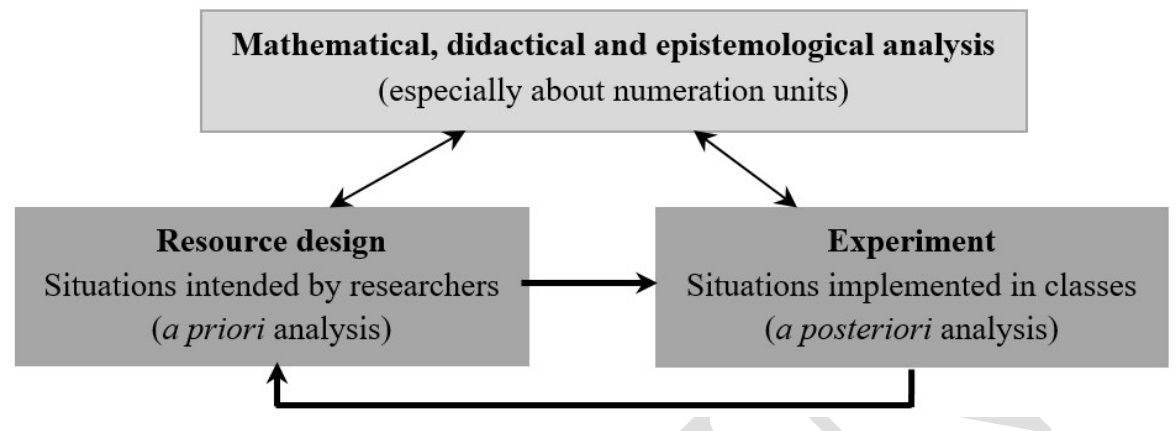

Fig. 1 General methodology showing the design and experimentation cycle.

In order to produce a resource that can be used by teachers, it is essential to go back and forth between the design stage and the analysis of the actual implementation (Tempier 2016). Therefore, our experiments re-examine the hypotheses put forward in the a priori analysis, by comparing them to the a posteriori analysis of the implemented situation (internal validation). On the one hand, observations of teachers help the researchers to better understand their practices and constraints. On the other hand, the analyses suggest ways to modify situations and/or their description. They also help to identify needs for teacher education.

We use situations in this article to refer to particular types of tasks (Watson et al. 2013), while the implementation environment is referred to as the milieu. The milieu of the situation refers to everything/anything with which the student can interact, and which provides feedback on their actions.

We draw upon the notion of the didactical variable to refer to variations in task design (Ko and Marton 2004). These planned variations in task design are under the teacher's control. The 'values' of the variable reflect the increasingly complex problems students are asked to solve, and dramatically change the knowledge that is engaged. As Watson et al. (2013) state,

To understand how tasks are linked in order to support teaching, it is important to understand the nature of the transformation of knowledge from implicit knowledge-inaction [...] to knowledge which is formulated, formalized, memorized, related to cultural knowledge, and so on. (p. 13)

Situations are theoretically divided into four phases: action, formulation, validation and institutionalization (Brousseau 1997). In the action phase, the student is faced with a milieu that can provide feedback on his or her actions. If the situation is well-designed, the student's implicit knowledge ${ }^{1}$ put into action is linked to the intended mathematical knowledge ${ }^{2}$ (Brousseau 1997; Watson et al. 2013). Here, action does not mean only the manipulation of materials; actions can be performed on symbolic objects such as written texts, either orally or in writing. The formulation phase corresponds to an explanation of the procedure. The validation phase consists of discussing validity and checking mathematical coherence. During institutionalization, the cultural

\footnotetext{
1 'Connaissance', in French
}

2 'Savoir', in French 
(mathematical) knowledge to be learned is situated in relation to students' implicit knowledge. These phases are not necessarily successive, and can be nested.

In the classroom, the teacher supports the smooth functioning of this process. Although in the example that follows, he or she does not construct the situation, the teacher does play an essential role in giving students autonomy to act (the action phase), the choice of the procedure that must be formulated or clarified (the formulation phase), and the links that they weave between implicit and targeted knowledge (the institutionalization phase).

The design of situations draws upon a preliminary analysis of place value, which, in turn, is based on earlier research on numeration units. That is the subject of the next section.

\section{Preliminary analysis of numeration units in relation to place value}

\subsection{A third system for representing numbers}

Dehaene (1992) argues there are three representations of cardinal numbers (the analog magnitude representation, the verbal word frame, and the visual Arabic frame), which are mentally manipulated in comparisons and calculations. He therefore proposes a three-code model of number processing, numerical activities that would rely on translating from one code to another. His model emphasizes that neither the written number nor the spoken number contain any semantic information perse.

Houdement and Chambris (2013), Houdement and Tempier (2015), and Chambris and Tempier (2017) introduced a hybrid number system (in the sense of Guitel 1975) for giving meaning to numbers and place value. This approach, which they call the 'base-ten numeration units system', is a regular, named- value, multiunit system (in the sense of Fuson 1990). Based upon an ordered list of numeration units, it sets aside the positional principle and draws only upon the decimal principle. Consistent with this earlier work, we propose a didactical variant (Figure 2) of the Dehaene (1992) model, which summarizes these three systems and their relations.

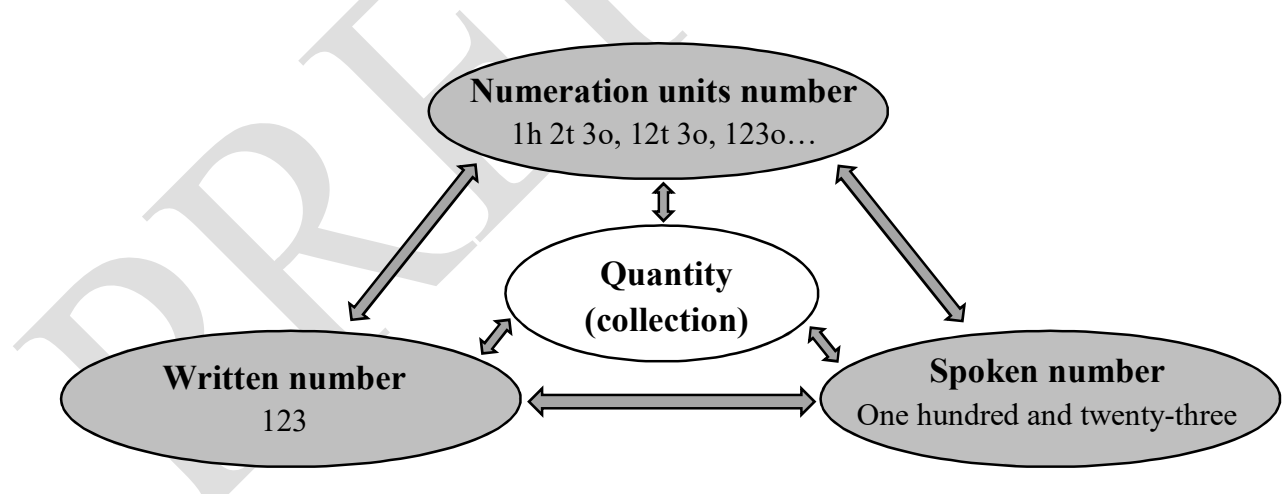

Fig. 2 Three systems for representing numbers.

We argue that there is great value in closely connecting these three systems, not only for place value understanding (see next sections), but also for the understanding of computational algorithms (Ma 1999), and the decimal form of rational numbers, especially decimal fractions. Furthermore, it may support the teaching of measurement units: length and mass, for example (Chambris 2008).

\subsection{Numeration units as a way to say and write numbers}

How numbers are spoken is naturally and significantly influenced by national culture, unlike the written number system, which is often imported from other civilizations at a later date. Therefore, how numbers are said is not always consistent with how they are written (Menninger 1969). It is well-known that the irregularities found in most European languages hide meanings structured on base-ten principles (Fuson et al. 1997). In France, for example, there are examples of groupings by 
twenty, heard in the number eighty (twenty multiplied by four) and ninety (twenty multiplied by four plus ten).

However, at least one oral number system stands out from the others (at least for numbers up to 100,000): the 'regular' named-value Chinese system (Fuson 1990). In this system, the number 29583 is spoken as "two ten thousand, nine thousand, five hundred, eight ten, three". In comparison, the French and English spoken systems are qualified by Fuson as 'irregular' systems as they are based on units that are either partly or fully spoken.

Numeration units are a very powerful alternative to spoken systems. The system is bivalent (oral and written) and place value (for written numbers) is explicit. It is very close to a 'regular' system. Moreover, a number can be written (or read) in multiple ways. For example, 512 can be written as: 5 hundreds, 1 ten, and 2 ones - or 5 hundreds and 12 ones — or 4 hundreds, 11 tens, and 2 ones — or 4 hundreds and 112 ones. It is a base-ten language that overcomes the irregularities of the standard spoken system and provides an alternative way to say a written number ( 72 is 7 tens, and 2 ones). It can also help to connect written and spoken numbers: in French, 72 is spoken as 'sixty twelve', which is also 6 tens and 12 ones, which is also 7 tens and 2 ones. In our work, we seek to define a canonical form, in which the number of units of each rank is smaller than ten. This form is congruent with how digits are written (but less congruent with how they are said). For example, 5 hundreds, 1 ten, and 2 ones is the canonical form, which is congruent with the written number 512 , while 5 hundreds and 12 ones is a non-canonical form that is congruent with the spoken number (cinq-centdouze in French, five hundred and twelve in English).

Another issue concerns numeration units that are not a faithful copy of the base-ten units described above. For small numbers, the numeration unit 'ten' is spoken differently. English uses the suffix 'ty' (fifty, sixty), while French uses 'ante' (cinquante, soixante). 'Hundred' and 'thousand' are spoken in English and French (five hundred, five thousand; cinq cents, cinq mille). French uses cent as the number word for 'hundred', but centaine as the numeration unit. 'Ten-thousands', 'hundredthousands', 'ten-millions', 'hundred-millions', etc. are not used to say numbers, either in English or French. Above 9999, only some base-ten numeration units are used orally, namely the powers of one thousand: thousand, million, and billion. The link between larger oral and written numbers (above 9999) is even more complex, a point that was made very clear by Fuson (1990):

To avoid the necessity of memorizing a huge list of multiunit names, most systems of number words meet this problem by creating certain large multiunits within which a small list of multiunit names is reused. Thus, in English very large numbers are chunked into large multiunits of a thousand, and the smaller multiunits of hundred and ten are used within these thousand-unit chunks. (p. 351)

It is the same in French: large numbers (in everyday language) also use base-1000. Therefore: (1) three-digit numbers play a fundamental role in learning the words for larger numbers; and

(2) learning how to say large numbers (over 9999), and translating spoken numbers into written numbers requires "reunitizing" (Baturo 2000). In this context, Chambris and Tempier (2017) propose that teaching should include, in addition to the base-ten numeration unit system, the base1000 system, and the link between them (the dual numeration unit system).

\subsection{Quantities as a support to give meaning to numeration units}

Appropriate manipulatives are useful to help students create mental images of numeration units, and give sense to the conversion of ten units into one ten and vice versa (Fuson et al. 1997). Problemsolving, material-based actions, such as grouping or partitioning with base-ten models (e.g., bundles of ten sticks), or pre-grouped base-ten models (plastic cubes, longs, flats, etc.) are common in educational materials (Ross 1989; Fuson and Briars 1990; Fuson et al. 1997). However, the introduction of such materials into the classroom - even those with the semiotic potential to demonstrate the idea of the unit — does not guarantee that the student is able to construct the concept 
(Bartolini Bussi and Mariotti 2002; Fuson et al. 1997; Baturo 2000). As Brissiaud (2005) notes, students who associate a representation of a quantity (with some base-ten material) with a written number can give the illusion of understanding; in fact, their reasoning may lack a link with the underlying groupings. Fuson (1990), Ross (1989), Hiebert and Wearne (1992), and Baturo (2000) point out the difficulty of passing from the grouping of objects into tens, to the concept of the group as a unit and, conversely, spotting the group of ten hidden in the notation. Finally, Chandler and Kamii (2009) highlight that the monetary equivalence 1 dime $=10$ pennies is obvious to adults, but not so simple for young students.

\subsection{Relation between units to understand place value and computation}

Barr (1978) finds a correlation between a poor understanding of numeration principles and poor performance in computational algorithms. Students who are comfortable with additive or subtractive algorithms that involve two-digit numbers are not necessarily able to extend this skill to three or more digit numbers (Thomas 2004). It is crucial that teachers know how to identify, and explain to their students, the links between numeration (concepts) and computation (procedures), what Ma (1999) refers to as a Profound Understanding of Fundamental Mathematics. In a study of pre-service trainee teachers in the United States, Thanheiser (2012) shows how carrying and borrowing in an additive or subtractive computation algorithm can be difficult to explain. Numeration units and their relations play a key role in this respect.

The (symmetrical) relation between ones and tens has been widely studied (e.g., Ross 1989; Fosnot and Dolk 2001; Chandler and Kamii 2009), whether as the organization of a collection, or as an additive or subtractive calculation (mental, online, or in-column). Coordinating these two units (and not just juxtaposing them) influences the understanding of larger numbers (Thomas 2004; Steffe and Cobb 1988). But being able to coordinate tens and ones does not guarantee an extension to numbers larger than one hundred, and the latter appears to remain difficult (Bednarz and Janvier 1982; Baturo 2000; Thomas 2004).

This observation is consistent with the mathematical analysis: the move from an $n$-digit number to a $(n+1)$-digit number increments by 1 the number of numeration units. On the other hand, the number of relations between these numeration units increases by $n$ : from $\left(\begin{array}{l}2 \\ n\end{array}\right)$ to $\left(\begin{array}{c}2 \\ n+1\end{array}\right)$ for $n \geq 2$ and the ratios between the two units in question vary from 1:10 to $1: 10^{\mathrm{n}-1}$. The student must therefore consider more relations, which can be integrated/remembered only if they understand numeration units as part of a coherent, regular system consisting of ordered units, and a 1:10 ratio between consecutive units. In other words,

place value is continuous (i.e., across whole-number and decimal-fraction places), bidirectional (to the left is 10 times larger in value $-\times 10$; to the right is 10 times smaller in value $-\div 10$ ), and exponential (i.e., nonadjacent places are related by powers of 10 $-10^{2}, 10^{3}$, etc.). (Baturo 2000, p. 96)

This level of abstraction requires the simultaneous understanding that ten units of a rank are, at the same time, one unit of an immediately higher rank (Fosnot and Dolk 2001).

Unitizing requires that children use number to count not only objects but also groupsand to count them both simultaneously. The whole is thus seen as a group of a number of objects. The parts together become the new whole, and the parts (the objects in the group) and the whole can be considered simultaneously. (Fosnot and Dolk 2001, p. 11)

\subsection{Towards the design of reference situations}

In the previous section, we argue that there is great value in closely connecting the three number representation systems (eventually using manipulatives): the written number, the spoken number 
and the numeration units number (Figure 2). A challenge is to identify specific conditions that can help students to construct a full or partial abstraction of place value (Chandler and Kamii 2009). How can positional and decimal principles be integrated into task sequences?

\section{Design of reference situations}

\subsection{The root situation}

For the design of situations, we relied on both our preliminary analysis, presented in the previous sections, and the fundamental situation of numbers ${ }^{3}$ proposed by Brousseau (1995) in his Theory of Didactical Situations. The fundamental situation considers the whole number as a discrete measure of quantity, and it is used in early number learning (Dorier 2015). We therefore adopted it for our study of primary school learning. In our work, students are shown collections that may include existing groupings, which encourages them to use quantitative reasoning to construct arithmetic reasoning (Nunes et al. 2016). To simulate an ordinary classroom situation, materials and organizational conditions were as similar as possible to day-to-day teaching practices. A consequence of this is that students could have less autonomy than in Brousseau's situations.

Although collections provided a milieu, they were not always physically available to students: some were shown, or simply evoked by words or in drawings. Students were asked to associate a written number with a quantity (collection) or, conversely, produce a collection from a written number. The challenge was not to manipulate collections, but rather to anticipate the effects of actions on manipulatives (Brousseau 1997). Written quantities used numeration units from grade 2. The aim is that these units become an element of the milieu that helps to evoke different groupings of the collection, and encourages students to reason without having to pack or unpack the collection. The situation requires learning about conversions between units: both higher (superunitising) and lower order (subunitising) (Baturo 2000).

\subsection{Description of the reference situations}

Two reference situations are used:

- Collection counting consists of writing the number corresponding to a quantity from a collection of objects, or a numeration unit number.

- Collection ordering is the inverse. A collection of objects or numeration units number must be produced from a written number.

In collection ordering a constraint can be introduced (e.g., no hundred group is available). Although this is similar to the 'Candy Factory' situation (Bowers et al. 1999), here we use it specifically for place value work, without extending it to computation techniques.

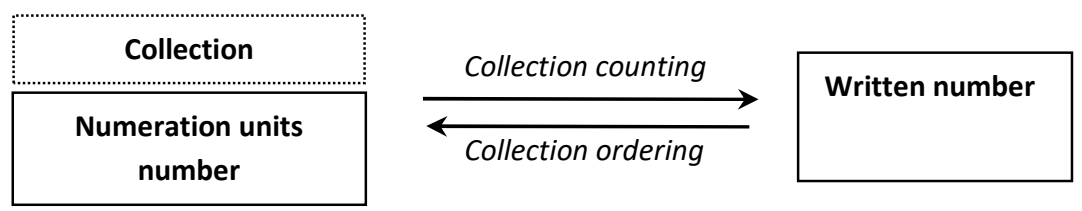

Fig. 3 The two reference situations.

\footnotetext{
${ }^{3}$ An example for children aged 5/6: "There is paint in these pots. You have to get the paintbrushes from over there and put one in each pot. You must bring back all the paintbrushes at once. There mustn't be a paintbrush that isn't in a pot, or a pot that doesn't have a paintbrush. If you make a mistake, you'll have to collect all of the paintbrushes, bring them back and try again" (Brousseau 1995; see also Dorier 2015).
} 
These situations meet Ross' (1989) concern; "Pupils need to engage in problem-solving tasks that challenge them to think about useful ways to partition and compose numbers" (p. 50).

\section{The two milieux: collections or numeration units}

In both reference situations, the presence of the collection ${ }^{4}$ can influence students' actions. For example, it enables them to make a grouping or trade, leading to an initial appropriation of units. Table 1 shows an example of a problem for each situation in which the collection is available or not. If it is not, students can make a drawing and simulate grouping or trading.

Table 1. The two reference situations with collections in the milieu.

\begin{tabular}{|l|l|l|l|}
\hline \multicolumn{2}{|c|}{ Collection counting } & \multicolumn{2}{c|}{ Collection ordering } \\
\hline Example situation & $\begin{array}{l}\text { We need to order 302 cubes. How many bundles } \\
\text { of ten cubes and single cubes can we order? }\end{array}$ \\
\hline How many cubes are there in this collection? & Same action \\
\hline
\end{tabular}

When the collection is not available in the milieu, we describe the quantity with numeration units. The student can then group or trade by drawing the collection, but he or she is encouraged to reason directly using units.

Table 2. The two reference situations with numeration units in the milieu.

\begin{tabular}{|c|c|}
\hline Collection counting & Collection ordering \\
\hline \multicolumn{2}{|l|}{ Example situation } \\
\hline $\begin{array}{l}\text { How many sticks are there in the collection of } 1 \\
\text { hundred (sticks), } 20 \text { tens (sticks), and } 2 \text { sticks? }\end{array}$ & $\begin{array}{l}\text { We need to order } 302 \text { sticks. How many tens of } \\
\text { sticks and single sticks can we order? }\end{array}$ \\
\hline \multicolumn{2}{|l|}{ Targeted actions } \\
\hline $\begin{array}{l}\text { Compose the number, with conversions between } \\
\text { units (into higher-value units): } 20 \text { tens }=2 \text { hundreds } \\
\text { (because } 10 \text { tens }=1 \text { hundred). }\end{array}$ & $\begin{array}{l}\text { Decompose the number, with conversions between } \\
\text { units (into lower-value units): } 302=30 \text { tens and } 2 \\
\text { ones (because } 1 \text { hundred }=10 \text { tens, } 3 \text { hundreds }=30 \\
\text { tens). }\end{array}$ \\
\hline
\end{tabular}

Collections can be present in the classroom and be used, or not, to illustrate the problem and validate students' responses. In our experiments with grades 1 and 2, the collection is present (either initially, or to be built). With grades 3 to 5, even when working on large numbers (over 1000) the collection is used initially to show quantities corresponding to each unit.

\footnotetext{
${ }^{4}$ Like Van de Walle et al. (2010) we distinguish between groupable manipulatives (wooden sticks, bundles of ten sticks tied with rubber bands, bundles of one hundred sticks with 10 tens sticks in a bag, etc.), and pregrouped and trading manipulatives (base-ten blocks: longs for tens, flats for hundreds, etc.).
} 


\subsection{An essential didactical variable: the organization of the collection or number of units of each rank}

The organization of the collection is a didactical variable that is critical in building positional and decimal principles. When the collection is designated with numeration units, this didactical variable corresponds to the number of units of each rank. Table 3 summarizes variations (Ko and Marton 2004) in the organization of the collection, and the number of units of each order in relation to the targeted mathematical knowledge. The absence of a grouping (no unit of a rank), requires the use of the digit 0 to write the number. The organization of the collection in relation to the task is expected to engage " "regular ten-for-one and one-for-ten trades' conceptual structures" without changing the initial quantity (Fuson 1990, p. 350).

Table 3. Mathematical notions related to variations in the organization of the collection or number of units of each rank.

\begin{tabular}{|l|l|l|l|l|}
\hline $\begin{array}{l}\text { Organization } \\
\text { of the } \\
\text { collection }\end{array}$ & $\begin{array}{l}\text { Collection 'in } \\
\text { bulk'. }\end{array}$ & $\begin{array}{l}\text { Collection totally } \\
\text { grouped (up to nine } \\
\text { units of each rank). }\end{array}$ & $\begin{array}{l}\text { Collection partially } \\
\text { grouped (ten or } \\
\text { more units of one } \\
\text { (or more) rank. }\end{array}$ & $\begin{array}{l}\text { Absence of a } \\
\text { grouping type. }\end{array}$ \\
\hline $\begin{array}{l}\text { Variable: } \\
\text { number of } \\
\text { units of } \text { each } \\
\text { rank }\end{array}$ & $\begin{array}{l}\text { Up to nine units of } \\
\text { all ranks. }\end{array}$ & $\begin{array}{l}\text { Ten or more units } \\
\text { of one (or more) } \\
\text { rank. }\end{array}$ & $\begin{array}{l}\text { Absence of a unit at } \\
\text { one (or more) rank. }\end{array}$ \\
\hline $\begin{array}{l}\text { Mathematical } \\
\text { issues }\end{array}$ & $\begin{array}{l}\text { Initial approach to } \\
\text { positional and } \\
\text { decimal principles } \\
\text { (grouping, trading). }\end{array}$ & $\begin{array}{l}\text { Positional } \\
\text { principle: } \\
\text { association between } \\
\text { units and places in } \\
\text { the written number. }\end{array}$ & $\begin{array}{l}\text { Decimal principle: } \\
\text { relations between } \\
\text { units. Conversions } \\
\text { between } \\
\text { numeration units. }\end{array}$ & $\begin{array}{l}\text { Role of 0 in the } \\
\text { written number } \\
\text { (positional } \\
\text { principle). }\end{array}$ \\
\hline
\end{tabular}

The transition from collections to numeration units (described in the previous section) should facilitate the transition from ten-for-one trades to conversions between units and written mark techniques (e.g., $265=26$ tens and 5 ones by 'cutting' 265 into 26 and 5).

\section{Experiments}

Drawing upon this model, we designed situations at all grades (1 to 5) of primary school education. Houdement and Tempier (2015) described some elements of the implementation in grades 1 to 3 . Here, we look in detail at an iconic grade 3 situation: the introduction to the thousand. In France, grade 3 students are usually taught about relations between several consecutive units, which lay the foundations for the decimal numbers studied in grade 4 .

Here, we focus on two tasks that are part of a six-task sequence that includes three collection counting and three collection ordering tasks. 


\subsection{The sequence of six tasks}

Table 4. The three variants of the grade 3 counting situation.

\begin{tabular}{|c|c|c|c|c|}
\hline \multirow{3}{*}{$\begin{array}{l}\text { Collection } \\
\text { counting }\end{array}$} & $\begin{array}{l}\text { Task 1: } \\
\text { Counting a } \\
\text { bulk } \\
\text { collection. }\end{array}$ & 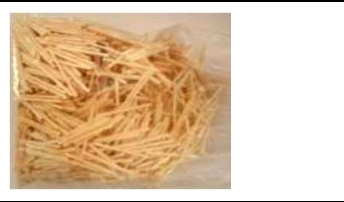 & $\begin{array}{l}\text { How many } \\
\text { sticks are there? }\end{array}$ & $\begin{array}{l}\text { The collection is } \\
\text { present; children } \\
\text { can handle it in } \\
\text { order to group by } \\
\text { tens, hundreds, etc. }\end{array}$ \\
\hline & $\begin{array}{l}\text { Task 2: } \\
\text { Counting a } \\
\text { completely } \\
\text { ordered } \\
\text { collection }\end{array}$ & $x_{2}$ & $\begin{array}{l}1 \text { thousand } \\
\text { sticks, } 4 \text { tens of } \\
\text { sticks, and } \\
5 \text { single sticks. } \\
\text { How many } \\
\text { sticks are there? }\end{array}$ & $\begin{array}{l}\text { The collection is } \\
\text { present, but } \\
\text { children cannot } \\
\text { handle it. They can } \\
\text { use analogical } \\
\text { representations } \\
\text { (photos) or } \\
\text { numeration units. }\end{array}$ \\
\hline & $\begin{array}{l}\text { Task 3: } \\
\text { Counting the } \\
\text { union of two } \\
\text { collections }\end{array}$ & $\begin{array}{l}1^{\text {st }} \text { collection: } 2 \text { thousan } \\
\text { ten, and } 3 \text { ones. } \\
2^{\text {nd }} \text { collection: } 4 \text { hundrec } \\
2 \text { ones. } \\
\text { How many sticks are the } \\
\text { choose one of } 31215 ; 32\end{array}$ & $\begin{array}{l}8 \text { hundreds, } 1 \\
1 \text { thousand, and } \\
\text { e? Students } \\
5 ; 3315 ; 4215 \text {. }\end{array}$ & $\begin{array}{l}\text { The collection is } \\
\text { suggested through } \\
\text { numeration units. }\end{array}$ \\
\hline
\end{tabular}

Varying the number of groups of each rank (more or less than ten) supports an evolution in the understanding of units. Task 3 , with more than ten "units of a rank" after putting together the two collections, is the most difficult.

Table 5. The three variants of the grade 3 ordering situation.

\begin{tabular}{|c|c|c|c|}
\hline \multirow{3}{*}{$\begin{array}{l}\text { Collection } \\
\text { ordering }\end{array}$} & $\begin{array}{l}\text { Task 4: Ordering a } \\
\text { collection of sticks. } \\
\text { No bundles of } 1000 \\
\text { sticks are available. }\end{array}$ & $\begin{array}{l}\text { We need to buy } 2615 \text { sticks, but the } \\
\text { seller has sold out of bundles of } 1000 \\
\text { sticks. How many bundles of one } \\
\text { hundred sticks, bundles of ten sticks, and } \\
\text { single sticks should we order? }\end{array}$ & \multirow{3}{*}{$\begin{array}{l}\text { The } \\
\text { collection is } \\
\text { suggested } \\
\text { through } \\
\text { numeration } \\
\text { units. }\end{array}$} \\
\hline & $\begin{array}{l}\text { Task 5: Ordering a } \\
\text { collection of sticks. } \\
\text { Only } 1 \text { bundle of } \\
1000 \text { sticks is } \\
\text { available. }\end{array}$ & $\begin{array}{l}\text { We need to buy } 3167 \text { sticks, but the } \\
\text { seller has only } 1 \text { bundle of } 1000 \text { sticks. } \\
\text { How many bundles of one hundred } \\
\text { sticks, bundles of ten sticks, and single } \\
\text { sticks should we order? }\end{array}$ & \\
\hline & $\begin{array}{l}\text { Task 6: Ordering a } \\
\text { collection of sticks. } \\
\text { No bundles of } 100 \\
\text { and } 1000 \text { sticks are } \\
\text { available. }\end{array}$ & $\begin{array}{l}\text { We need to buy } 2375 \text { sticks, but the } \\
\text { seller has sold out of bundles of } 100 \text { and } \\
1000 \text { sticks. How many bundles of ten } \\
\text { sticks, and single sticks should we order? }\end{array}$ & \\
\hline
\end{tabular}

These three tasks are variations on the collection ordering task and concern the availability of groups (the stock of sticks) of each rank.

In the following, we only study tasks 3 and 4.

\section{A priori analysis of task 3}

Activities designed to strengthen the understanding of place value are often linked to the additive and subtractive computation of sums and differences (Ross 1989, Carpenter et al. 1998, McClain et al. 1998, Kamii and Joseph 2004). In particular, Kamii and Joseph (2004) argue that students should be allowed to invent their own techniques, rather than imposing traditional computational algorithms. We adopted this idea for the design of task 3 . Task 3 consists of determining the number of sticks that is obtained when two collections of sticks, described with numeration units, are 
combined. Students can choose from four options: three are predictable, wrong answers while the last option is correct (Table 4). They can change their initial response after discussion with peers. The challenge is to use the relations between numeration units to assign a single digit to each rank, which is an epistemological condition for writing numbers with digits.

The use of spoken number strategies (for instance counting by ones), is limited by the absence of collections in the milieu. Another difficulty is the amount of data: a written support is required. One initial strategy is to add units of the same rank, and write the quantity obtained in numeration units ( 3 thousands, 12 hundreds, 1 ten, and 5 ones). The conversion between hundreds and thousands helps the student to grasp the canonical form of the numeration unit (up to nine units in each rank, 4 thousands, 2 hundreds, 1 ten, and 5 ones). The written number (4215) is deduced using the positional principle.

Predictable errors consist in making a mistake in the conversion, or not carrying it out, leading to:

- juxtaposing the numbers of each unit (31215), or

- eliminating the tens digit of numbers that exceed ten units (3215), or

- adding the two digits of a unit if it is more than ten (3315).

Another strategy is to count each collection, and then to add the two written numbers. In this case, the error depends on how the student handles the carry-over process.

For the implementation in the classroom, the role of the teacher is particularly important in the formulation and validation phases. Although the numeration units that are used as a first step suggest collection groupings, students should gradually become independent of the manipulative context: they are expected to talk about numeration units rather than types of groupings, or even think in terms of groupings. At times, the teacher may decide to hide the collection in order to help students understand that, for example, 12 hundreds are equivalent to 1 thousand and 2 hundreds. This can enable students to anticipate actions on the collection and foster direct reasoning with numeration units, thereby initiating the decontextualization process. The collection can be reintroduced at a later stage for final verification. Teachers are expected to refer to numeration units rather than types of groupings. Linking these two strategies is, moreover, an opportunity for the teacher to institutionalize the relation between unit conversion and the (column) carrying-over process in the addition algorithm.

\section{A priori analysis of task 4}

In task 4, the teacher plays the role of a stick seller: he/she has a stock of sticks bundled into ones, tens, hundreds, and / or thousands. A written number is given to students. They do not have access to the collection and are asked to fill out the following purchase order: "...thousands of sticks, ...hundreds of sticks, ...tens of sticks, ...sticks". There are various ways to write the numeration unit number. In the collection ordering situation, the challenge is to use relations between the thousands and lower-ranked units to determine the different decompositions of the number. Task 4 principally targets conversions between thousands and hundreds. Students can use several strategies to order their 2615 sticks, options include:

- converting between numeration units: 2 thousands $=20$ hundreds and 20 hundreds +6 hundreds $=26$ hundreds;

- substituting the ones and tens by 0 in the written number 2615 , and reading this new number (2600) as the number 26 multiplied by 100 , which gives 2600 ;

- grouping or ungrouping, accompanied by a drawing the collection;

- counting orally by ones, based on a collection ("one hundred", "two hundred", etc.) or additive decomposition $(100+100+100 \ldots)$. 
Dividing 2615 by 100 using computational techniques (in line or in column) is not expected at this grade under the current French curriculum.

The main predicted errors consist in either writing one-digit numbers for each unit (i.e. 6 hundreds 1 ten 5 ones), or adding the thousands to the hundreds (i.e. 8 hundreds, 1 ten, 5 ones), or not taking account of the constraint (i.e. 2 thousands 6 hundreds 1 ten 5 ones, despite the fact that no thousands are available). All of these errors are related to the difficulty of perceiving the hundreds contained in the thousands and the dominance of the canonical decomposition $(2615=2$ thousands 6 hundreds 1 ten 5 ones).

In task 4, the teacher should highlight the strategy for converting from thousands to hundreds, based on the different number decompositions obtained by students. It should be possible for them to verify their answers using unit conversions rather than the collection, for example: 26 hundreds 1 ten 5 ones $=20$ hundreds and 6 hundreds 1 ten 5 ones $=2$ thousands 6 hundreds 1 ten 5 ones $=2615$. Numeration units play an important role in the institutionalization of knowledge ('savoir') because these symbolic expressions are independent of the nature of the collection: they reflect the mathematical knowledge that students should acquire to solve the problem.

We are aware that students might simply see the task as a mechanical technique consisting of the truncation of the written number, without properly understanding the relations between units. For this reason, tasks 5 and 6 involve variations on the available stock, requiring students to use other conversions between units and carry out different decompositions.

\subsection{Experiment: an implementation at grade 3 (a posteriori analysis)}

This section addresses the appropriation of tasks and the use of numeration units in the first design cycle. Four grade 3 teachers participated in the experiment; they implemented the six tasks given above. We observed three or four sessions with each class. The analysis of situations in which students were asked to solve tasks 1 and 2 validated their usefulness in learning the positional principle, especially the role of 0 to mark the absence of a unit in the written number. The comparison of success rates between the initial and final assessments confirmed ${ }^{5}$ that many students were able to correct their initial errors (e.g., 3 tens and 6 hundreds $=36$ or 63). Observations showed that teachers had a good understanding of how the two tasks were linked and the mathematical knowledge involved. In particular, they correctly used variations in the order of presentation of each unit, and the rank or absence of a unit. They took students' errors into account in order to institutionalize the positional principle, often with the help of the place value chart, which associates each rank with a unit.

Students trying to solve task 4 made the errors predicted in the a priori analysis (e.g., 6 hundreds 1 ten 5 ones for 2615). Some students tried to use a technique based on a direct reading of the written number and seemed to think that "you have to take the two digits on the left to determine the number of hundreds", as in the cases where no thousand was available. As teachers presented variations of the available stock of sticks, these techniques, which are inconsistent with conversions between units, were put aside. For example, when students were asked to order 3167 sticks, with only one bundle of thousand sticks available they wrote ' 1 thousand 31 hundreds 6 tens 7 ones': this suggests that they have trouble adjusting to this new task. Therefore, the experiment showed the appropriation of didactical variables by teachers, consistent with the targeted knowledge.

\footnotetext{
${ }^{5}$ For example, the success rate for the item ' 3 tens 6 hundreds' in the initial assessment (before teaching thousands) was $52 \%$, compared to $73 \%$ for the more difficult item ' 3 tens 1 thousand' in the final assessment, after the sequence.
} 
However, the analysis of the implementation of tasks 3, 4 and 5, which involved the decimal principle, revealed unexpected differences compared to the a priori analysis. To illustrate this, we report two phenomena related to their implementation.

\section{Task 3 implementation: A systematic return to the collection}

In task 3 the collection is named with numeration units. This led most teachers to describe the task in terms of units and draw a final conclusion: this was a new practice for some. However, the presence of numeration units does not ensure that they will be used to teach conversions between them: they were often used only in reference to the collection (sticks, for example) in order to carry out or describe groupings. For instance, in one class, a student (Mark) is asked to draw the union of two collections on the blackboard (a box for thousands, a bag for hundreds, etc.). Mark finds it difficult to count 12 bags, so the teacher asks another student (Joris) to help him:

Joris: In fact when you have twelve, you have more hundreds [...] If you had ten hundreds, what does it correspond to?

Teacher: What can you do? If you had ten bags, what would you do?

Mark: Ah yes, a thousand.

The student draws a new box on the blackboard.

Teacher: You'll put the ten in a box. [...] When we have ten bags, we can put them in a box. [...] So, as soon as it exceeds ten, we can put them in a 'thousand' box.

Although students can use numeration units orally, the teacher reformulates their words by describing manipulative actions (put ten bags in a box). However, students are expected to use basic unit equivalences ( 10 ones $=1$ ten, 10 tens $=1$ hundred, etc.) in order to perform conversions between them (e.g., 12 hundreds $=1$ thousand and 2 hundreds). Collections, which help to give meaning to these units, can be used but in this case, the back-and-forth interaction between the collection and the system of numeration units must be planned, in order to decontextualize ${ }^{6}$ and generalize $^{7}$ the relation (see the a priori analysis) and support conceptualization.

Furthermore, our observations showed that when numeration units are used in the classroom, they are used only to perform oral conversions. For instance, in the previous example, the teacher did not transpose, either orally or in writing, Joris' suggestion into: 12 hundreds $=1$ thousand and 2 hundreds. When another student explains what he did to find the total number of sticks ("seven hundreds and three hundreds makes ten"), the teacher does not propose the associated conversion ( 7 hundreds +3 hundreds $=10$ hundreds $=1$ thousand) but continues to refer to collections ("I transformed my bags; I put them in a box, because I have ten"). This does not help students to master the task of converting written units, nor facilitate the transition to numeration units.

Our experimental design did not anticipate that teachers would manage the situation in this way: we had assumed that numeration units would be both spoken and written, and linked by equations. Our observations show that this practice is not obvious for teachers and should be given more attention.

\section{Task 4 implementation: $A$ return to the ones}

The main issue in the ordering situation (task 4) is to explain to students why their answers are correct or incorrect. Two scenarios were observed: either the teacher evaluated the answers and provided no feedback, or feedback was provided to the student. In the latter case, numeration units

\footnotetext{
${ }^{6}$ For example, 'one hundred' can designate one hundred sticks, one hundred euros, or one hundred grams. The use of 'packs' or 'boxes' only applies to the particular context of sticks.

${ }^{7}$ When the relations between units increase in number, the reference to groupings of groupings becomes difficult (Bednarz and Janvier 1982). For example, to determine the number of tens in 3 thousands it is more economical to use the equality $3 \mathrm{th}=30 \mathrm{~h}=300 \mathrm{t}$ ( or $3000=30 \times 100=300 \times 10$ ) than double unpacking into thousands' groups and hundreds' groups.
} 
were typically converted into the 'number' of sticks. For example, in one class, students were asked to order 3167 sticks, with only one bundle of a thousand available in the stock. The teacher used Sophia's wrong answer ( 1 thousand 31 hundreds 6 tens 7 ones) to explore the problem with the class. She wrote the answer on the board and asked the student to check their response.

Mrs. B: That number, with thirty-one hundreds of sticks, what is it? Sophia, if I tell you thirty-one hundreds of sticks, what is that number?

Faced with the student's lack of response, Mrs. B takes out the collection grouping.

Mrs. B: Look. I have thirty-one hundreds of sticks, what's that number? Come and write it for me on the board.

The student comes to the board.

Mrs. B: I have my bags there; I have thirty-one bags. [...] Thirty-one hundred sticks...if I have ten groups like that, how many sticks will I get?

Sophia: One thousand.

Mrs B: One thousand. If I have thirty packets like that?

Sophia: Three thousand.

Mrs B: And if I add a packet of one hundred, it will make?

Sophia: Three thousand.

The teacher's closed questions did not encourage the student to convert 31 hundreds into 3 thousands and 1 hundred, and simply relied on the minimal knowledge "ten hundreds is one thousand". If Sophia had been given the opportunity to use the collection named in her answer, she could have checked it herself, by reorganizing the collection and comparing 4 thousands, 1 hundred, 6 tens, and 7 ones with 3167 . This shows that the teacher did not use the potential of the collection either to explore conversions between units, or to verify the student's answer.

\section{Conclusion}

Our research into learning and teaching place value at primary school is based on the development of close connections between three number representation systems, namely, the two standard ways (i.e., written and spoken numbers) and a third system, numeration unit numbers, which are written as they are spoken. Our epistemological and didactical analysis highlighted the influence of numeration units on understanding place value. In order to identify the specific conditions needed for the integration of numeration units into task sequences we used the didactical engineering approach. We designed two reference situations for grades 1 to 5 : collection counting and collection ordering. The challenge is to enrich students' (and teachers') understanding of numeration units. Tasks gradually become more complex. They begin with the designation of collections (tens, hundreds, etc.) in terms of numeration units and go on to use these units and their relations to understand, designate, and calculate with written digits. This evolution is supported by a set of increasingly difficult constraints (didactical variables), which are a function of the knowledge to be learned and anticipated errors that should be eliminated.

The grade 3 empirical instructional examples highlight various phenomena. First of all, the reference tasks can be effective. Students begin to use numeration units as initially intended, i.e., to speak or write about the collection in general without using the names of manipulatives such as bundles of sticks. Many students can also use numeration units to propose conversions between units. However, some teachers do not support this level of abstraction. For example, in the counting situation, they systematically use the names of manipulatives, or refer to grouping actions to describe conversions between units (for example, "bags that we put in boxes"). Thus, they do not address conversions using numeration units. In the ordering situation, they refer to the ones (or the written number) when checking students' answers in the class discussion phase, and rarely spend time on conversions between successive units (hundreds and thousands, for example). We did not anticipate that teachers would find it difficult to initiate the process of decontextualization based on numeration units and their relations, and it appears that they believe that this is beyond the abilities of grade 3 students. 
We are increasingly convinced that the teaching of place value should be at the core of teachers' education. In France, as in other Western countries (Ma 1999), primary school teachers are unaware of the impact of place value understanding on the learning of mathematics. Furthermore, unlike Asian teachers, they are not immersed in a social environment where numeration units are usually spoken out loud, highlighting the value of the digit in the number. In addition to its relevance for student learning, we think that the numeration units system could be also a powerful tool in teacher education, as it makes visible the relationships between place value knowledge, decimal numbers, computation and measurement units. This underlines the huge need for more teacher educationexceeded only by the need for more research into teacher education.

\section{References}

Artigue, M. (2009). Didactical design in mathematics education. In C. Winslow (Ed.), Nordic Research in Mathematics Education, Proceedings from NORMA08 (pp. 7-16). Rotterdam: Sense Publishers.

Barr, D. C. (1978). A comparison of three methods of introducing two-digit numeration. Journal for Research in Mathematics Education, 9(1), 33-43.

Bartolini Bussi, M. G., \& Mariotti, M. A. (2002). Semiotic mediation in the mathematics classroom: Artifacts and signs after a Vygotskian perspective. In L. English, M. G. Bartolini Bussi, G. Jones, R. Lesh, \& D. Tirosh (Eds.), Handbook of international research in mathematics education, second revised edition (pp. 746-783). Mahwah, NJ: Lawrence Erlbaum.

Baturo, A. (2000). Construction of a numeration model: A theoretical analysis. In J. Bana \& A. Chapman (Eds.), In Proceedings 23rd Annual Conference of the Mathematics Education Research Group of Australasia (pp. 95-103).

Bednarz, N., \& Janvier, B. (1982). The understanding of numeration in primary school. Educational Studies in Mathematics, 13(1), 33-57.

Bowers, J., Cobb, P., \& McClain, K. (1999). The evolution of mathematical practices: A case study. Cognition and Instruction, 17(1), 25-64.

Brissiaud, R. (2005). Comprendre la numération décimale: Les deux formes de verbalisme qui donnent l'illusion de cette compréhension. Rééducation Orthophonique, 223, 225-238.

Brousseau, G. (1995). Les mathématiques à l'école. Bulletin de l'APMEP, 400, 831-850.

Brousseau, G. (1997). Theory of didactical situations in mathematics (Edited and translated by N. Balacheff, M. Cooper, R. Sutherland, \& V. Warfield). Dordrecht, The Netherlands: Kluwer.

Carpenter, T. P., Franke, M. L., Jacobs, V. R., Fennema, E., \& Empson, S. B. (1998). A longitudinal study of invention and understanding in children's multidigit addition and subtraction. Journal for Research in Mathematics Education, 29(1), 3-20.

Chambris, C. (2008). Relations entre les grandeurs et les nombres dans les mathématiques de l'école primaire. Évolution de l'enseignement au cours du 20e siècle. Connaissances des élèves actuels. Université Paris Diderot, Thesis.

Chambris, C., \& Tempier, F. (2017). Dealing with large numbers: What is important for students and teachers to know? In T. Dooley \& G. Gueudet (Eds.), Proceedings of the Tenth Congress of the European Society for Research in Mathematics Education (pp. 245-252). Dublin, Ireland: DCU Institute of Education and ERME.

Chandler, C. C., \& Kamii, C. (2009). Giving change when payment is made with a dime: The difficulty of tens and ones. Journal for Research in Mathematics Education, 40(2), 97-118.

Dehaene, S. (1992). Varieties of numerical abilities. Cognition, 44(1), 1-42.

Dorier, J. L. (2015). Key issues for teaching numbers within Brousseau's theory of didactical situations, In X. H. Sun, B. Kaur, \& J. Novotna (Eds.), Proceedings of the Twenty-third ICMI Study: Primary mathematics study on whole numbers. (pp. 76-83). Macao, China.

Fosnot, C. T, \& Dolk, M. (2001). Young mathematicians at work. Constructing number sense, addition, and subtraction. Portsmouth, NH: Heinemann. 
Fuson K. C. (1990). Conceptual structures for multiunit numbers: Implications for learning and teaching multidigit addition, subtraction, and place value. Cognition and Instruction, 7(4), 343403.

Fuson K. C., \& Briars D. J. (1990). Using a base-ten blocks learning/teaching approach for first and second grade place-value and multidigit addition and subtraction. Journal for Research in Mathematics Education, 21(3), 180-226.

Fuson, K. C., Wearne, D., Hiebert, J., Human, P., Murray, H., Olivier, A., Carpenter, T. P., \& Fennema, E. (1997). Children's conceptual structures for multidigit numbers and methods of multidigit addition and subtraction. Journal for Research in Mathematics Education, 28, 130162.

Godino, J., Batanero, C., Contreras, A., Estepa, A., Lacasta, E. \& Wilhemi, M. (2013). Didactic engineering as design-based research in mathematics education. In B. Ubuz, Ç. Haser, \& M. A. Mariotti (Eds.), Proceedings of the Eight Congress of the European Society for Research in Mathematics Education (pp. 2810-2819). Antalya, Turkey.

Guitel, G. (1975). Histoire comparée des numérations écrites. Paris: Flammarion.

Hiebert, J., \& Wearne, D. (1992). Links between teaching and learning place value with understanding in first grade. Journal for research in mathematics education, 23(2), 98-122.

Houdement, C., \& Chambris, C. (2013). Why and how to introduce numbers units in 1st and 2nd grades. In B. Ubuz, Ç. Haser, M. A. Mariotti (Eds.), Proceedings of the Eight Congress of the European Mathematical Society for Research in Mathematics Education (pp. 313-322). Antalya, Turkey.

Houdement, C. \& Tempier, F. (2015) Teaching numeration units: Why, how and limits. In X. H. Sun, B. Kaur, \& J. Novotna (Eds.), Proceedings of the Twenty-third ICMI Study: Primary mathematics study on whole numbers. (pp. 99-106). Macao, China.

Ifrah, G. (1981). Histoire universelle des chiffres. Paris: Editions Seghers.

Kamii, C., \& Joseph, L. (2004). Young children continue to reinvent arithmetic, 2nd grade: Implications of Piaget's theory. New York: Teachers College Press.

Ko, P. Y., \& Marton, F. (2004). Variation and the secret of the virtuoso. In F. Marton, A. B. Tsui, P. Chik, P. Y. Ko, \& M. L. Lo (Eds.), Classroom discourse and the space of learning (pp. 4362). Mahwah, N.J: Lawrence Erlbaum.

Ma, L. (1999). Knowing and teaching elementary mathematics: Teachers' understanding of fundamental mathematics in China and the United States. Hillsdale, NJ: Lawrence Erlbaum.

Ma, L., \& Kessel, C. (2018). The theory of school arithmetic: Whole numbers. In M. G. Bartolini Bussi, \& X. H. Sun, (Eds.). Building the foundation: Whole numbers in the primary grades (pp. 439-464). Cham: New ICMI Study Series, Springer.

McClain, K. Cobb, P., \& Bowers, J. (1998). A contextual investigation of three-digit addition and subtraction. In L. J. Morrow, \& M. J. Kenney (Eds.), The teaching and learning of algorithms in school mathematics (pp. 141-150). Reston, VA: National Council of Teachers of Mathematics.

Margolinas, C., \& Drijvers, P. (2015). Didactical engineering in France: An insider's and an outsider's view on its foundations, its practice and its impact. ZDM Mathematics Education, 47(6), 893-903.

Menninger, K. (1969). Number words and number symbols. A cultural history of numbers. Translated from the revised German edition (Göttingen, 1958). Cambridge, Mass: M.I.T. Press.

Nunes, T., Dorneles, B. V., Lin, P. J., \& Rathgeb-Schnierer, E. (2016). Teaching and learning about whole numbers in primary school. In Teaching and learning about whole numbers in primary school. ICME-13 Topical Surveys (pp. 1-50). Cham: Springer International Publishing.

Perrin-Glorian, M. J. (2011). L'ingénierie didactique à l'interface de la recherche avec l'enseignement. Développement de ressources et formation des enseignants. In C. Margolinas et al. (Eds.), En amont et en aval des ingénieries didactiques (pp. 57-78). Grenoble: La Pensée Sauvage.

Proust, C. (2000). La multiplication babylonienne: La part non écrite du calcul. Revue d'Histoire des Mathématiques, 6, 293-303.

Ross, S. H. (1989). Parts, wholes, and place value: A developmental view. The Arithmetic Teacher, $36(6), 47-51$. 
Steffe, L. P., \& Cobb, P. (1988). Construction of arithmetical meanings and strategies. New York, NY: Springer Verlag.

Stevin, S. (1585). La Disme [De Thiende]. Premierement descripte en Flameng, \& maintenant convertie en Francois. In L'arithmétique (1958) (pp. 206-213). Leyde: Plantin.

Sun, X. H., Kaur, B., \& Novotná, J. (Eds.) (2015). Primary mathematics study on whole numbers. Proceedings of the Twenty-third ICMI Study. Macao, China.

Sun, X. H., et al. (2018). The what and why of whole number arithmetic: Foundational ideas from history, language and societal changes. In M. G. Bartolini Bussi \& X. H Sun (Eds.), Building the foundation: Whole numbers in the primary grades (pp. 91-124). Cham : New ICMI Study Series, Springer.

Tempier, F. (2013). La numération décimale de position à l'école primaire. Une ingénierie didactique pour le développement d'une ressource. Université Paris Diderot, Thesis.

Tempier, F. (2016). New perspectives for didactical engineering. An example for the development of a resource for teaching decimal number system. Journal of Mathematics Teacher Education, $19(2-3), 261-276$.

Thanheiser, E. (2012). Understanding multidigit whole numbers: The role of knowledge components, connections, and context in understanding regrouping $3+-$ digit numbers. The Journal of Mathematical Behavior, 31(2), 220-234.

Thomas, N. (2004). The development of structure in the number system. In M. J. Hoines \& A. B. Fuglestad (Eds.), 28th Conference of the International Group for the Psychology of Mathematics Education (pp. 305-312). Bergen: Bergen University College Press.

Van de Walle, J. A., Karp, K. S., \& Bay-Williams, J. M. (2010). Elementary and middle school mathematics: Teaching developmentally (Seventh edition). Boston, MA: Allyn \& Bacon.

Watson, A., Ohtani, M., Ainley, J., Bolite Frant, J., Doorman, M., Kieran, C., Leung, A., Margolinas, C., Sullivan, P., Thompson, D., \& Yang, Y. (2013). Introduction. In C. Margolinas (Ed.) Task design in mathematics education (pp. 9-15). Proceedings of ICMI Study 22. 